Volume 8, No.1.1, 2019

International Journal of Advanced Trends in Computer Science and Engineering

Available Online at http://www.warse.org/IJATCSE/static/pdf/file/ijatcse5981.12019.pdf

https://doi.org/10.30534/ijatcse/2019/5981.12019

\title{
Study of Losses in the Production Line of Large Footwear Company
}

\author{
Marcelo S. Alencar, Hélio M. Mesquita, Thiago T. Alencar \\ Institute of Advanced Studies in Communications \\ Federal University of Campina Grande \\ Campina Grande, Brazil \\ malencar@iecom.org.br,hm mesquita@hotmail.com, thiagota.thiago@gmail.com
}

\begin{abstract}
The article analyzes the production loss, also referred to as reject, in the largest footwear producer of the World, the Alpargatas company. The article presents a discussion of the probabilistic modelling, the development of a stochastic model, that uses It ${ }^{\wedge}$ o stochastic integration, based on temporal series provided by the company, and the identification of eventual solutions to the loss of production.
\end{abstract}

Key words : Production Data, Stochastic Integration, Stochastic Modeling

\section{INTRODUCTION}

This research was solicited by Alpargatas S/A, the largest own brand and licensed, sporting goods, footwear and textile company in Brazil, which has 6,500 regular and outsourced employees, and largest shoe producer in the World, with an annual revenue of US\$ 1,130 billion from sales of 228,265 million units of sandals, footwear, clothing and accessories in the internal market, in 2013. The research was performed at the Institute of Advanced Studies in Communications (Iecom) in cooperation with the Technical-Scientific Association Ernesto Luiz de Oliveira Jnior (Atecel).

The Iecom was responsible for the project development, and the Atecel was responsible for the financial management of the project. Both entities are private right, non-profit entity, with the basic finality of supporting and making research and extension programs at the Federal University of Campina Grande (UFCG) viable.

The article discusses the problem of loss of production, also known as reject, in the Alpargatas company. In the following sections, the article presents a discussion of the probabilistic modeling, and the development of a stochastic model, that uses Itô stochastic integration. The obtained results are based on temporal series provided by the company. The article identifies eventual solutions to the large reject generated by the company, and proposes a diagnostic to the production problem. To the best of the author's knowledge, there are no similar models, that use stochastic differential equations, another form of It ${ }^{\wedge} \mathrm{o}$ stochastic integration, in the solution of problems related to production line losses. A discussion is presented, that relate the proposed method to the classical Statistical Process Control (SPC) of production.

\section{ALPARGATAS PRODUCTION SYSTEM}

The Alpargatas Company started production in 1907. Currently its business is rising due to the growth of sales, and consequent increase in production and quarters, and the company is the largest producer of footwear in the World. The Havaianas sandals, a World success, were created in 1962, with one model and a mix of four colors. Today there are 68 models for the national market, and 18 exclusive models for export with a large pallet of colors.

Havaianas are $80 \%$ of the rubber sandals sold in the country. Alpargatas is the leading company in the market in the footwear sector. The Campina Grande unit, differently from the other companies of the group, does not have satellite factories. This industrial complex, formed by four factories and two Distribution Centers (DC), works in three shifts, from Monday to Saturday [1].

The Production Planning and Control (PPC) has been adopted to respond to market changes, and allows a continuous flow of materials, people and information, able to feed this system, in order that the productive system meets the organization's strategic goals [2].

The production averages $90 \%$ of its total capacity, which is 700.000 pairs/day. The creation of products is done in the $\mathrm{S}$ ao Paulo headquarters, and the development in the laboratories of the Campina Grande plant. The sandals are produced through an industrialization process, in which, $40 \%$ are residuals of the sandals, and $60 \%$ chemical products and input material.

The productive flux has several steps in which the raw materials are transformed in compounds, all of these processes involve human interference, to put and remove loads, and make adjustments in the instrumentation of the control equipment [3]. 
The formulation absorbs part of the reject and scraps of previous processes $(40 \%)$, with errors (raw materials, manpower, instrumentation) from those batches now present in the formulation, in which new virgin (prime) raw materials, that were not used, are going to be mixed into.

When the compound starts a new cycle, it already has a certain amount of reject incorporated into it, from the previous process. After several generations of production, the reject takes on an average value, as in its formation it is composed of residuals from different products with separate reject [4].

This means that there is an initial value of loss at each start of process, and at the end the other residuals are added to it, which can reach up to $20 \%$, depending on the degree of difficulty in producing the article, and the amount of time to set the process parameters, as in the case of products from a new collection. To define the scope of the problem, Alpargatas has provided some files with information about the reject of the company.

\section{PERFORMANCE COMPARISON}

In this research, a study of the literature and the existing procedures was done, to serve as a basis for the modelling of the random temporal series which characterizes the reject of the company. Generally speaking, the Statistic Process Control (SPC) is used to characterize common events, and specific events which disturb the production [2][4].

However, as the procedure is based on statistics, it does not involve the time variable, and does not permit an inference or prevision of tendencies for the reject. The Theory of Stochastic Processes (TSP) is a powerful tool for the study of random temporal series, and permits the verification of the correlation between production factors, as well, as the prevision of future events, or their modelling.

\section{STUDY OF STATISTICAL CORRELATION}

The research was conducted under the agreement for a project on Research, Development and Innovation (RD\&I), signed between the Iecom, Alpargatas and Atecel, which resulted in a study on the possibility of solution for the reject problem using statistical correlation. This tool results from the study of stochastic processes.

A stochastic or random process is an extension of the random variable concept, which comprises the sample space, the set of processes and the associated probability density functions. In other words, a stochastic process is a family of random variables $\{X(t), t \in T\}$ defined on a probability space, and indexed by a time parameter $t$, which varies in a set $T$ [5][6].

\section{ANALYSIS USING STOCHASTIC INTEGERATION}

The stochastic processes are usually non-stationary, which means that their statistical averages, or moments, also vary with time. This makes it difficult to use correlation to treat them. In this case, the stochastic integration is a useful tool to attack the problem, to obtain a problem formulation, from the modeling of the reject based on a stochastic differential equation.

The stochastic calculus began with the study and modelling of market prices, this is, the fluctuation of the stock value as a function of time. In this case, the investors work based on the variation of the potential gain or loss, $\mathrm{dX}(\mathrm{t})$, as a proportion of the invested sum $X(t)$.

Therefore, in fact, what matters is the relative price $\mathrm{dX}(\mathrm{t}) / \mathrm{X}(\mathrm{t})$, of a certain asset, as it reacts to the market fluctuations, this is, it should be proportional to a Wiener process $\mathrm{W}(\mathrm{t})$ [7],

$$
d X(t)=\alpha X(t) d W(t)
$$

which is an informal manner to express the orresponding integral equation,

$$
X(t+\tau)-X(t)=\alpha \int_{t}^{t+\tau} X(u) d W(u)
$$

An immediate question associated to the equation solution is related to the non-differentiability of a Wiener process $W$ $(t)$, at any point in time. A way to circle the problem has been found, and is known as the theory of stochastic integrals, or the study of stochastic differential equations [8].

The Itô general stochastic equation is given by:

$$
d X(t)=a(X(t), t)) d t+b(X(t), t)) d W(t),
$$

in which $a(X(t), t))$ the drift function, or model trend and $b(X(t, t))$ is the dispersion function, volatility, of the stochastic process.

\section{Stochastic Model for the Reject Problem}

When formulating a stochastic model to represent the reject variation along with time, it is important to consider that the loss rate is proportional to the existing quantity. This can be expressed as [9],

$$
\frac{d X(t)}{d t}=\alpha X(t) .
$$


The incremental variation of the reject is proportional to the differential variation $d W(t)$ of a stochastic process, $W(t)$, which usually has a Gaussian distribution, multiplied by the existing quantity of material, $X(t)$, and adjusted by the parameter $\beta$, which remains to be found, based on the production specifications

$$
d X(t)=\beta X(t) d W(t)
$$

The process $W(t)$ is the result of a combination of all production errors, $W_{i}(t)$, which can be found in the industrial production line

$$
W(t)=\sum_{i=1}^{N} W_{i}(t)
$$

thus, by the Central Limit Theorem, $W(t)$ has a Gaussian probability distribution, with mean and variance given by:

$$
\begin{aligned}
& m_{W}(t)=\mathrm{E}[W(t)]=\sum_{i=1}^{N} \mathrm{E}\left[W_{i}(t)\right], \\
& \sigma_{W}^{2}(t)=V[W(t)]=\sum_{i=1}^{N} \mathrm{~V}\left[W_{i}(t)\right] .
\end{aligned}
$$

For stationary stochastic processes, the moments are independent of time, this is, $m_{W}(t)=m_{W}$ e $\sigma^{2}(t)=\sigma^{2}$. Combining both assumptions, results in the following stochastic differential equation [10]

$$
d X(t)=\alpha X(t) d t+\beta X(t) d W(t),
$$

which is the informal manner to write

$$
X(t+\tau)-X(t)=\alpha \int_{t}^{t+\tau} X(u) d u+\beta \int_{t}^{t+\tau} X(u) d W(u),
$$

in which $\mathrm{X}(\mathrm{T}+\tau)$ represents the future value of the process $\mathrm{X}(\mathrm{t})$, that is $\tau$ time units in advance. In order to solve the stochastic differential equation obtained with the reject model, using the generic formulation for stochastic differential equations, one must consider that the drift function is proportional to the stochastic process, this is, $\mathrm{a}(\mathrm{X}(\mathrm{t}), \mathrm{t})=\alpha \mathrm{X}(\mathrm{t})$, that the dispersion function is modeled as $b(X(t), t)=\beta X(t)$, and that one can use the Ito^ formula for the $\log$ arithm function $\mathrm{f}(\mathrm{x}, \mathrm{t})=\log (\mathrm{x})[11]$.

Following the procedure established by Itô, for the solution of the equation, one obtains,

$$
\begin{gathered}
\frac{\partial f(x, t)}{\partial t}=0, \\
\frac{\partial f(x, t)}{\partial x}=\frac{1}{x}, \\
\frac{\partial^{2} f(x, t)}{\partial^{2} x}=-\frac{1}{x^{2}} .
\end{gathered}
$$

Thus,

$$
d \log (X(t))=\frac{\alpha X(t) d t}{X(t)}+\frac{\beta X(t) d W(t)}{X(t)}-\frac{\beta^{2} X^{2}(t) d t}{2 X^{2}(t)},
$$

this is,

$$
d \log (X(t))=\left(\alpha-\frac{\beta^{2}}{2}\right) d t+\beta d W(t)
$$

integration in time, one obtains

$$
\log (X(t))=\log (X(0))+\left(\alpha-\frac{\beta^{2}}{2}\right) t+\beta W(t)
$$

taking the logarithm inverse function, results in

$X(t)=X(0) \cdot \exp \left(\alpha-\frac{\beta^{2}}{2}\right) t \cdot \exp (\beta W(t))$

in which $X(0)$ represents the initial value of the process, that remains to be found, based on the problem constraints.

The preceding formula can be written, in a simplified form, as

$$
X(t)=X(0) \cdot e^{\left(\alpha-\frac{\beta^{2}}{2}\right) t+\beta W(t)} .
$$

This solution shows, for the proposed stochastic process, that the reject grows exponentially in time, controlled by the parameters $\alpha$ and $\beta$, that also remain to be determined. It is possible to note a random variation in the curve, as a result of the stochastic process $W(t)$.

For a stochastic process, $W(t)$, that corresponds to the total production line loss, if its distribution is Gaussian, it I possible to compute the associated reject distribution, using the transformation of probability density function mathematical operation.

The expected value of the process, $X(t)$, is given by,

$$
\begin{aligned}
\mathrm{E}[X(t)] & =\mathrm{E}[X(0)] \cdot \exp \left(\alpha-\frac{\beta^{2}}{2}\right) t \cdot \mathrm{E}[\exp (\beta W(t))] \\
& =\mathrm{E}[X(0)] e^{\alpha t} .
\end{aligned}
$$


Therefore, according to the obtained mathematical model the average value of the reject grows exponentially, for the specified conditions. The initial mean value of the process,

$\mathrm{E}[X(0)]$, should be determined from the data delivered by the industrial plant, as well as the estimate of the parameter, $\alpha$, that controls the curve.

Figure 1 illustrates a stochastic process, that represents the evolution of the reject with time, as well as, the initial mean value of the process $\mathrm{E}[X(t)]$, as a dotted curve.

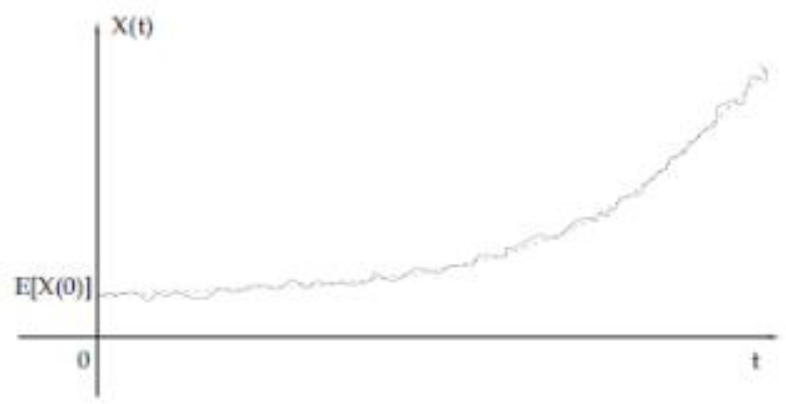

Figure 1: Stochastic process, that represents the evolution of the reject with time

Note that the stochastic process is non-stationary, in the long run, because its average value depends on time. Besides, the probability distribution of process $\mathrm{X}(\mathrm{t})$, that represents the loss, is not Gaussian, as is usually assumed in the computation of losses using the usual theory of process statistical control.

\section{DIAGNOSTIC}

From the preliminary analysis of the temporal series, one can verify that it is not possible to use the classic linear prediction method to model the reject in a production line, because the stochastic process is non-stationary.

Of course, the linear prediction model can be used to forecast in the short run, because it does not rely on production parameters. But, as mentioned, it requires that the process that models que reject be stationary in the considered interval.

The proposed model, which uses the It ${ }^{\wedge} \mathrm{o}$ stochastic integral, allows to obtain a mathematical formula that reveals an exponential growth for the average value of the reject, that is controlled by production parameters, which can be determined from statistical moments that depend on the nature of the productive process. The method can be used to estimate the reject generation in other type of industry, with different products and distinct production lines.

The stochastic modelling of the production process permits to predict the short, or medium, term behavior of the reject series. It can also estimate unusual situations, periodicities, trends, and changes that are not visible in the observation of the raw series. This can be used to reduce the losses in the production line to a limited percentage of the total production, and built and automated control procedure, as compared to the manual evaluation and correction procedure currently used.

\section{OBTAINED RESULTS}

The model that uses stochastic integration permits a medium to long term prediction of the reject series, which represents an advantage in relation to the traditional statistical methods, such as the process statistical control, but requires the determination of specific parameters, which depend on data provided by the company.

In the studied case, the long term growth of the reject follows an exponential curve that presents a stochastic variation with time. That variation depends on the addition of all the errors along the production process.

Figure 2 shows the measured evolution of the reject, with time, for the Traditional type of sandal, the best seller. It can be seen that the average loss follows an exponential curve. Figure 3 shows the measured evolution of the reject, with time, for the Color type of sandal. As the curve shows, the average loss also follows an exponential curve, with a different pattern.

Figure 4 shows the measured evolution of the reject, with time, for the Casual type of sandal. The average loss follows an exponential curve, with a high value for the $\alpha$ parameter.

The mathematical model indicates the correction measures that should be taken to adjust the production line, and reduce the reject. Figure 5 shows the measured evolution of the reject, with time, for some sandals, after the correction measures are in place.

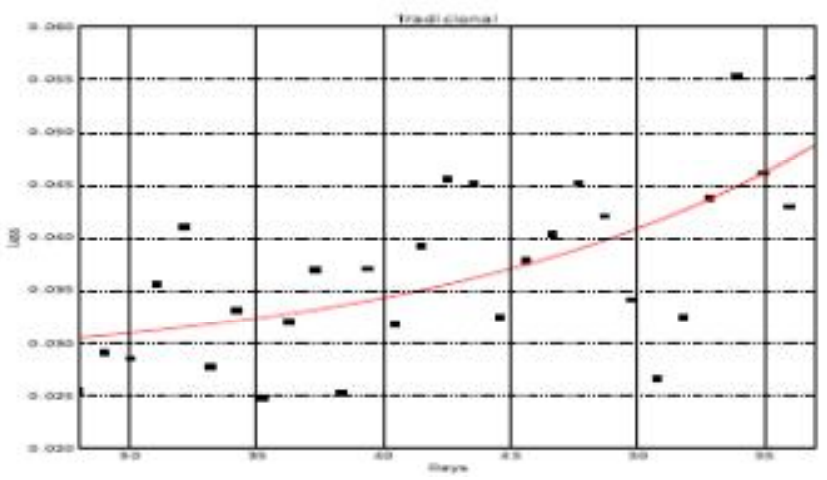

Figure 2: Measured evolution of the reject, with time, for the Traditional type of sandal

Although the instantaneous variation presents a Gaussian characteristic, because it is the result of multiple effects along the productive chain, the final process, which models the reject, does not have a Gaussian distribution. Its distribution is likely to be asymmetric. 


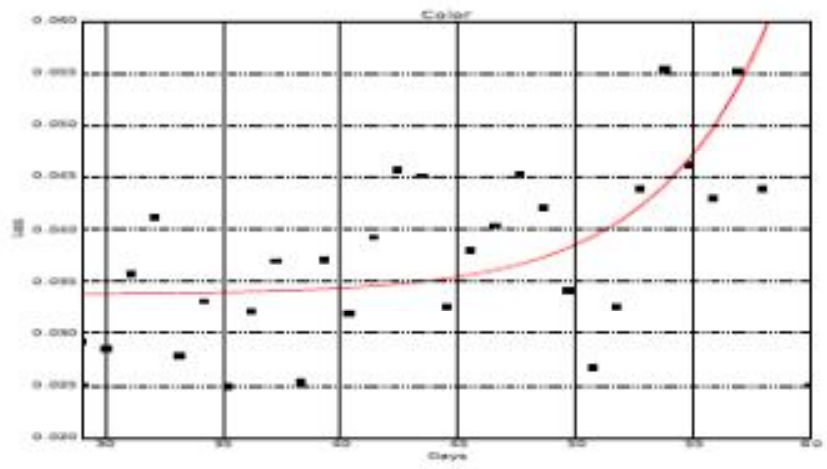

Figure 3: Measured evolution of the reject, with time, for the Color type of sandal.

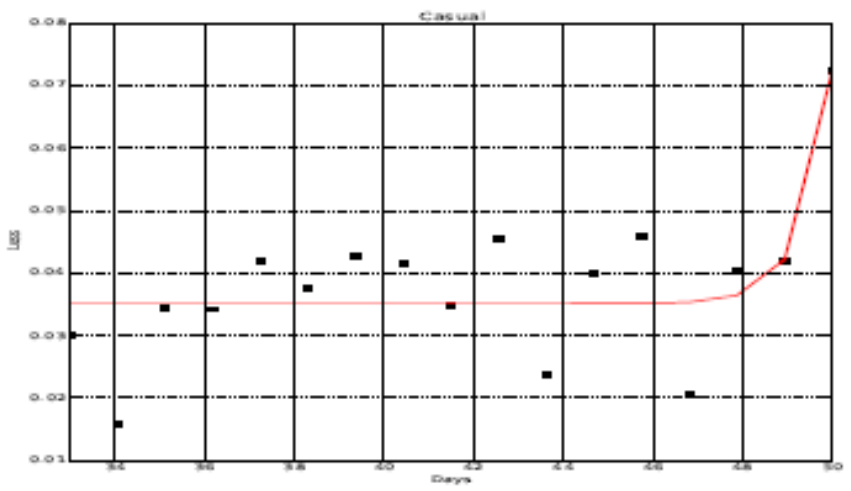

Figure 4: Measured evolution of the reject, with time, for the Casual type of sandal.

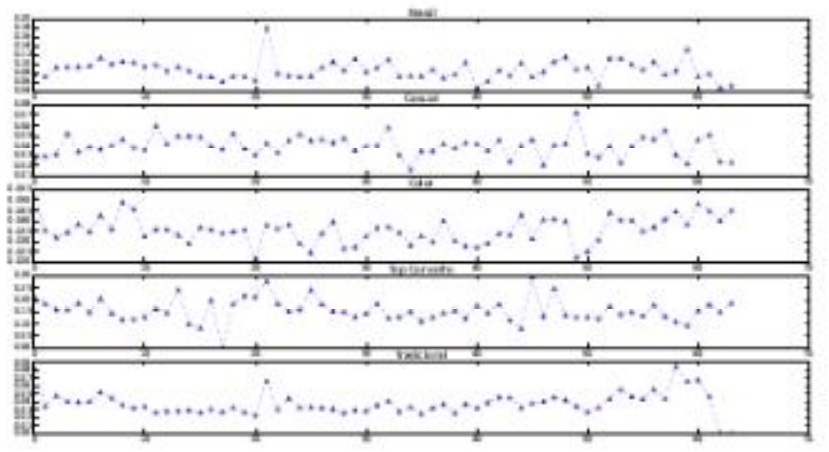

Figure 5: Measured evolution of the reject, with time, for a few sandals, after the correction measures are taken.

The modeling indicates that is could be necessary to define an adequate percentage of reduction in the recycled material that is re-inserted in the production line, such that, the reject is kept within specifications, for a given period of time.

Besides, from the detailed analysis and processing of the series, it is possible to indicate the most adequate periods to adjust the recycling process, using the reject.

\section{CONCLUSIONS AND FUTURE WORK}

Among the activities of this research project, one can cite the acquisition of information from the company, the production data and reject analysis, the mathematical modeling using stochastic differential equations, and the proposal of a general solution, in which specific solutions are pointed to the company discretion.

The future work involves a mathematical study to determine the probability distribution of the reject, as well as, the computation of the moments to help determine the common of specific causes of losses in the production line, a work related to the process statistical control.

It is possible to implement the model as a computer algorithm, to forecast the loss statistics, to predict reject behavior from initial conditions, for any period in time, to take adequate measures to decrease the losses, and the associated costs. This can be done by estimating the parameters that govern the growth curve.

\section{ACKNOWLEDGEMENT}

The authors acknowledge the support of the Institute for Advanced Studies in Communications (Iecom), of the National Council for Research and Development (CNPq), and of the Graduate Program in Electrical Engineering (Copele), Federal University of Campina Grande (UFCG).

\section{REFERENCES}

[1] M'arcio Utsch and Jos'e Roberto Letiere. "Divulgac , ao dos Resultados 4T13 e 2013". Relat 'orio t'ecnico, Alpargatas S/A, 2014.

[2] Jaqueline Guimaraes Santos. "Production Planning and Control of Hawaiian: A Case Study in Alpargatas of Campina Grande". Revista Gest ao Industrial, 9(3):623-640, 2013.

[3] M'arcio Utsch. "Relat 'orio da Administrac, ao 2013". Relat'orio t'ecnico, Alpargatas S/A, 2014.

[4] Marileudo Marinho Soares, Robson Fernandes Barbosa, Walber Anderson de Sousa Oliveira, Perseu Padrede Macedo, and Leonardo Lincoln Quirino Duarte. "An'alise do Sistema de Produc, ao em uma Empresa Calc sadista: Caso da Alpargatas S.A.”. In XXXI Encontro Nacional de Engenharia de Produc, ao, pages 1-14, Belo Horizonte, Brasil, Outubro 2011.

[5] Marcelo S. Alencar and Raphael T. Alencar. Probability Theory. Momentum Press, LLC, ISBN-13: 978-1-60650-747-6 (print), New York, USA, 2016.

[6] Marcelo S. Alencar and Valdemar C. da Rocha Jr. Communication Systems. Springer, ISBN 0-387-25481-1, Boston, USA, 2005. https://doi.org/10.1007/b138483 
Marcelo S. Alencar et al., International Journal of Advanced Trends in Computer Science and Engineering, 8(1.1), 2019, 338 - 343

[7] Zdzislaw Brzezniak and Tomasz Zastawniak. Basic Stochastic Processes. Springer, London, Great Britain, 2006.

[8] Kiyoshi It ^o. "Stochastic integral". Proceedings of the Imperial Academy, 8(20):519-524, 1944.

[9] J. R. Movellan. "Tutorial on Stochastic Differential Equations". Technical report, MPLab Tutorials Version 06.1, 2011.

[10] Markus Rei_. "Stochastic Differential Equations". Lecture notes, Institute of Applied Mathematics, University of Heidelberg, 2007.

[11] Kiyoshi It ^o. "On a Stochastic Integral Equation". Proceedings of the Imperial Academy, 2(22):32-35, 1946. 